- land plants. But fossil flowers are scarce, and botanists have long speculated about what the first blooms might have looked like. "The flower was responsible for this massive diversification," says Soltis. "We can't understand how we got to where we are without understanding what the first one was like."

About eight years ago, the eFLOWER project enlisted a team of botanical experts to find out. The team catalogued more than 20 traits in nearly 800 species. They then matched these data with molecular studies of evolutionary relationships, and used statistical modelling to infer the features of the earliest flower.

\section{BUDDING DOUBTS}

The results painted a picture of a flower that was symmetric around a central axis and contained both male and female sex organs. The eFLOWER models also suggested that many organs in the first flower were whorled, meaning they were arranged regularly in concentric circles when viewed from above. But the authors also warned that statistical support for some of these findings was weak.

Even so, the idea of a whorled ancestral flower shocked some people, says Hervé Sauquet, a lead author on the eFLOWER paper and an evolutionary biologist now at the Royal Botanic Garden in Sydney, Australia. Many plant scientists expected that the bloom's organs would have been staggered in a spiral coiled around a central axis. "It was a long-held dogma that was never confirmed," he says.

But what puzzled Sokoloff was that in Sauquet's analysis, the flower's petals and male reproductive parts were arranged in whorls, yet the female reproductive organs, carpels, were arranged in a spiral. He had never seen this combination of whorled and spiral organs in a single flower. Moreover, he and his colleagues suggest that it might not be developmentally possible for plants to achieve two different arrangements of organs in one flower.

\section{"Things can be statistically possible without being biologically possible."}

That's because the organs emerge from the same region of the plant, Sokoloff says. In some whorled flowers, the position of the carpels dictates the position of the male reproductive organs. Sokoloff's team picked back through the eFLOWER database and found four examples in which whorled and spiral organs had been identified within the same flower. But after further analysis, they decided that each example contained only one type of reproductive organ.

Sauquet says that his team has since revisited those data and agreed with some, although not all, of Sokoloff's concerns. Repeating their analysis with an updated and expanded data set, they now find that all reproductive organs in the ancestral flower were probably whorled, he says. But some of the revised results had a relatively low degree of statistical support, just as the first analysis did. "It wasn't certain before, and it remains uncertain," Sauquet says. "We don't know the final answer yet."

Sokoloff says that a fundamental problem of eFLOWER's approach was evaluating each trait of a flower independently before assembling those traits into a coherent bloom. "They analysed the evolution of each character separately," he says. "But some combinations of characters are impossible."

Even so, Sauquet argues that the absence of a particular form in modern flowers does not mean that it never existed. "There are a lot of weird things that existed before that we cannot see nowadays," he says.

Settling the debate over the first flower will take a bigger database and more-sophisticated models, says Wenheng Zhang, who studies plant evolution at Virginia Commonwealth University in Richmond. But the eFLOWER effort is an example of how modern techniques can be married to classical morphology to tackle fundamental questions about plant origins, she says. "This kind of study redirects botanists to look at the morphology," Zhang says. "It just comes back to the basics." -

\title{
Child authors spark probe
}

\section{Researchers may have added relatives to papers to boost their chances at university.}

\section{BY MARK ZASTROW}

$\mathrm{T}$ he South Korean government is expanding an investigation into researchers who named their children as co-authors on papers. In some cases, the practice is thought to be intended to give the children an edge when applying to university, a highly competitive process in South Korea. The education ministry announced on 1 February that it would extend its original investigation, which last month identified
82 academic papers on which authors had named their children or relatives - many of them in middle or high school - as co-authors.

And on 4 February, the science ministry launched its own investigation into several of the country's elite technical universities, which had not been included in the education ministry's initial probe.

The 82 papers with child authors were uncovered in a month-long review of articles written by more than 70,000 full-time university staff members across arts and sciences over 10 years. The review was prompted by a single case of child authorship that came to light late last year, at Seoul National University.

The investigation results, released on 25 January, found examples from 29 South Korean universities. In 39 of the papers, the students seemed to have participated in the research as part of a programme related to their school curriculum; the other 43 appeared not to have, according to the investigation.
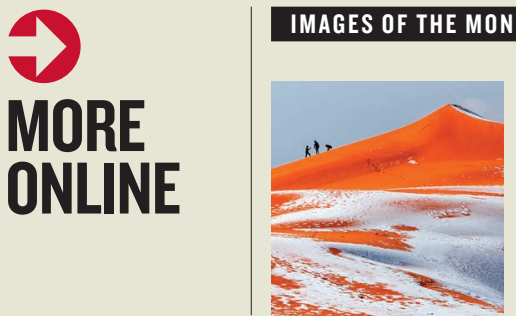

MORE NEWS

January's sharpest science shots, selected by Nature's photo team go.nature. com/2nh1pq2
- Physicists harness twisted mathematics to make powerful laser go.nature.com/2e5qu07

- Indian science budget fails to impress go.nature.com/2gsp3n6 - PubMed Commons closes its doors to comments go.nature.com/2elkyqa

\section{NATURE PODCAST}

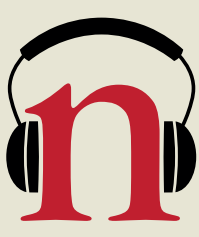

Crayfish clones; the social smarts of magpies; and building tougher wood nature.com/nature/ podcast 
The education ministry has not released the names of the researchers involved in the cases, nor the journals in which they published. However, according to South Korean media reports, many of the papers appeared in journals included in the Science Citation Index (SCI). The ministry told Nature that the initial review relied on universities to self-report cases, and was not exhaustive because many staff members were on their winter holidays.

\section{INDEXED PAPERS}

In its continuing probe, the education ministry intends to examine papers by South Korean authors indexed in citation databases, including the SCI, Web of Science and Scopus, and to cross-check the names against the family relationships of 76,000 full-time faculty members. The investigation will run until 16 March.

The ministry intends to refer each case to the corresponding university's research-ethics committee to confirm whether it constitutes misconduct or legitimate authorship. If the student co-authors did not participate in the research, academics will face possible disciplinary action, including dismissal, the ministry said.

So far, the most-affected universities include some of Seoul's elite tertiary institutions: Sungkyunkwan University (eight cases), Yonsei University (seven cases), Seoul National University and Kookmin University (six each). A Sungkyunkwan spokesperson confirmed that the university would be opening probes as per the ministry's request, including possible penalties of dismissal.

Yonsei University declined to answer Nature's questions about the investigation, pending further information from the government. A Seoul National University spokesperson emphasized that there has not yet been any finding suggesting that actual misconduct had occurred, and that its research-integrity committee would investigate all cases.

A spokesperson for Kookmin University told Nature that an initial review of the institution's cases indicated that the collaborations were legitimate. "We have some records and notes that their children participated in a lot of activities. So we think we don't have any problem," he said.

The practice has sparked a national outcry. In an editorial, the Korea Herald called the acts "no less than fraud, which greatly threatens the integrity of universities and education as a whole in Korea".

The education ministry said that any students listed as co-authors who did not participate in the research would have their university admission revoked.

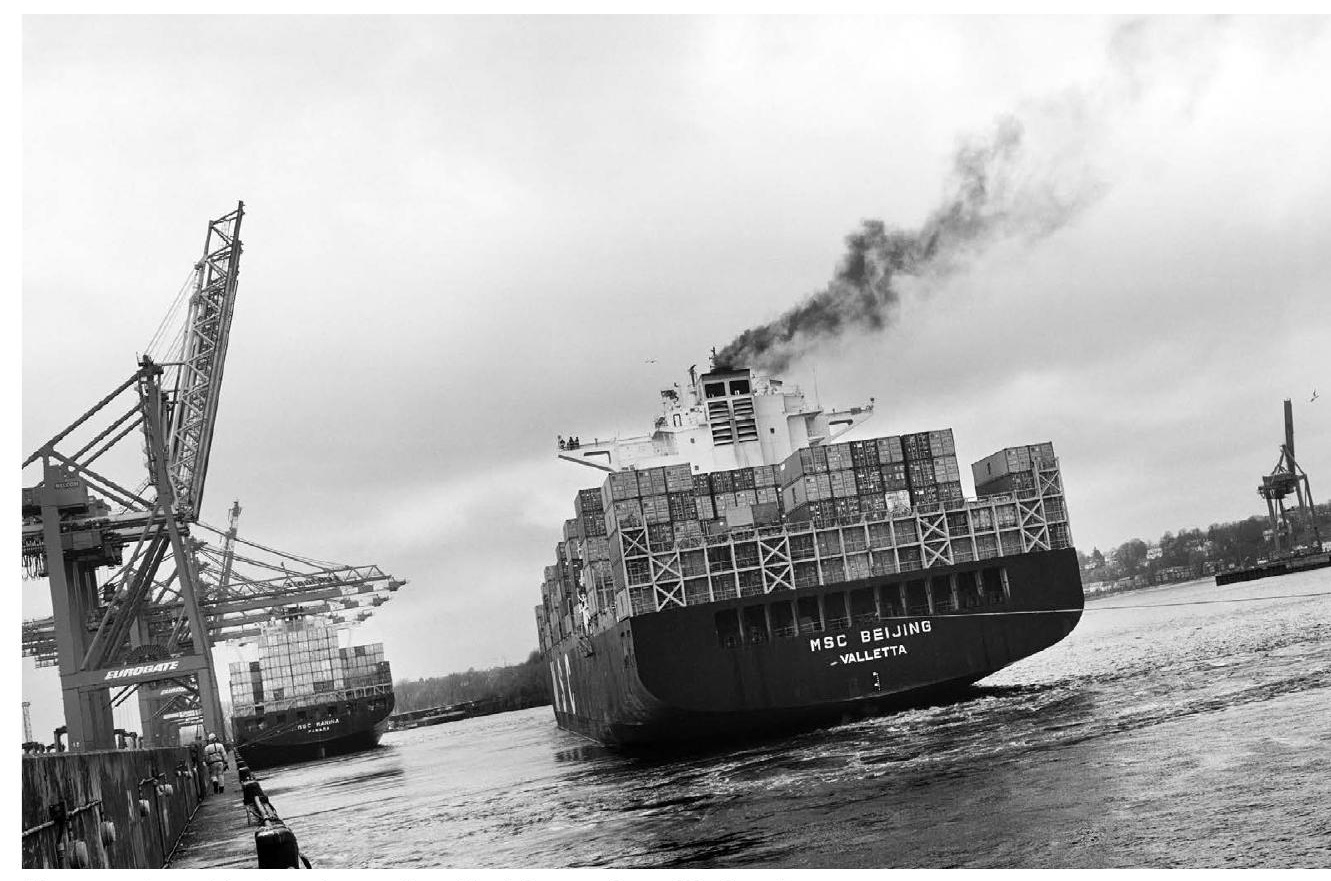

Most container ships burn heavy diesel fuel that produces black carbon.

AIR POLLUTION

UN targets black
carbon from ships

Nations are advancing efforts to reduce sooty emissions.

\section{BY JEFF TOLLEFSON}

$\mathrm{G}$ overnments are poised this week to begin discussing rules to curb black-carbon pollution from ships, after nearly seven years of preparation. The sooty emissions, which are produced by diesel engines, warm the climate and harm human health.

At a meeting in London, a panel of the United Nations International Maritime Organization (IMO) is expected to agree on measurement techniques to gather data that could support eventual regulations. That is the second step in a three-step process begun in 2011. Agreeing on a definition for black carbon took four years; the final step, writing rules, could take a few more.

Reducing the amount of black carbon emitted by ships could have a significant impact on the climate. The pollutant, a melange of particles and oil droplets that come in many shapes and sizes, is the second-largest driver of global warming - behind only carbon dioxide. Diesel engines, such as those in ships, account for around one-fifth of the world's black-carbon emissions, according to a study published in
2013 (T. C. Bond et al. J. Geophys. Res. Atmos. 118, 5380-5552; 2013).

The pollution is also dangerous when inhaled, in part because black-carbon particles collect other contaminants such as sulfuric acid and heavy metals - as they travel through the atmosphere. Advocates are pushing the IMO to speed up its negotiations, which involve more than 170 countries. "We really only have 90 minutes per year where we are actively discussing the topic, so it's easy to delay and to stall," says Bryan Comer, a senior researcher at the International Council on Clean Transportation, a non-profit research group in Washington DC.

Although global black-carbon emissions from diesel engines on land are roughly 20 times higher than those from ships' engines, the health and environmental impacts of shipping pollution hits many busy ports and coastal areas disproportionately hard, says Daniel Lack, an independent consultant in Brisbane, Australia. "When you concentrate all of these ships into specific areas, all of a sudden they become one of the most dominant sources of pollution."

One area of special concern is the rapidly melting Arctic. The region's shipping traffic 